\title{
Desenvolvimento de animações em livro digital para crianças surdas
}

Development of animations in digital book for deaf children

MUNIZ, Pablo Ferreira; Graduado; Universidade Federal do Maranhão - UFMA

pablommuniz@gmail.com

COSTA, Andréa Katiane Ferreira; Mestre; Universidade Federal do Maranhão - UFMA

andrea.katianefc@gmail.com

CRENZEL, Silvina Ruth; Doutora; Centro Universitário Carioca

silvinaphd@gmail.com

\section{Resumo}

Um livro digital infantil é formado a partir de uma narrativa digital, que permite soluções para conectar multimídia e interatividade com o objetivo de contar histórias. Sendo a Libras uma linguagem visual, este trabalho propõe, através de livro digital para crianças surdas, desenvolver e implementar animações que potencializem as chances de aprendizagem do português como segunda língua. A partir da história original - Guilherme Augusto Araújo Fernandes, de Mem Fox e Julie Vivas - os cenários e personagens foram refeitos para ambientá-los à realidade étnica brasileira e, em especial, dos tipos físicos presentes no Maranhão. As animações foram geradas com auxílio de softwares de edição gráfica. Através dos resultados desta pesquisa em Design Gráfico, visando a inclusão, será possível contribuir para criação de ferramentas para o planejamento de objetos educacionais e para a melhoria nos padrões educacionais de crianças surdas, a fim de se conseguir uma aprendizagem mais produtiva e interativa.

Palavras Chave: livro digital, animação infantil, inclusão.

\begin{abstract}
A children's digital book is made from a digital narrative, which allows solutions for connect multimedia and interactivity with the purpose of telling stories. Since Libras is a visual language, this term paper proposes, through a digital book for deaf children, to develop and implement animations that enhance the chances of them to learn the portuguese as second language. Starting from the original story - Guilherme Augusto Araújo Fernandes, from Mem Fox and Julie Vivas - the scenarios and characters were redesigned to bring them closer to the Brazilian ethnic reality, and especially the physical types present in Maranhão. The animations were generated with the help of softwares of graphic editing. Through the results of this research in Graphic Design, aiming at the inclusion, it will be possible to contribute to the creation of tools for planning educational objects and improving the educational standards of deaf children, in order to achieve a more productive and interactive learning.
\end{abstract}

Keywords: digital book, children's animation, inclusion. 


\section{Introdução}

A Língua Brasileira de Sinais (LIBRAS) é a primeira forma de comunicação do surdo brasileiro e é reconhecida como meio legal de comunicação e expressão pela Lei 10.436, de 24 de abril de 2002, regulamentada pelo Decreto lei no 5696 de 23 de dezembro de 2005 (BRASIL, 2002). A ampla integração social do surdo, por outro lado, demanda o acesso à língua majoritária de seu país, neste caso a língua portuguesa. Sendo que em poucos locais, há um intérprete de Libras, a fluência no português é fundamental para o melhor usufruto de seus direitos como também um caminho para pluralizar os espaços públicos e privados de frequentação dessas pessoas.

Além disso, quanto mais cedo a criança surda aprender o português como segunda língua, maiores as chances de vir a dominá-la plenamente. Antes dos 3 anos é um período-chave, em que as habilidades cognitivas (linguagem, memória, raciocínio) se iniciam e formam as bases do desenvolvimento da linguagem. Entre o nascimento e os 3 anos de idade é o chamado "período crítico de aquisição da língua", afirma Mayberry (1991). Nas línguas orais-auditivas a externalização e internalização da mensagem ocorre por via da voz e da audição, respectivamente. 0 processamento de linguagem da criança surda é baseado na percepção visual e na produção visiospacial, visto que nas línguas de sinais a mensagem é captada pela visão. (MAYBERRY, 1991) A visualidade a que o surdo é exposto, tão logo nasça, aponta caminhos e sustenta abordagens tangentes ao universo do design.

O design é um canalizador de linguagens diversas direcionado principalmente à visual e sendo a Libras uma linguagem visiospacial, o trabalho apresentado propõe, desenvolver e implementar curtas animações que potencializem as chances de aprendizado de crianças surdas em fase de alfabetização. A relação de elementos gráficos combinados à animação estimula a percepção, memorização e aprendizagem da mente ${ }^{1}$. No processo de alfabetização de deficientes auditivos, esses elementos visuais podem ser ainda mais relevantes, por este ser muito dependente da visão. O designer, na sua atribuição de tradutor intersemiótico e detentor de conhecimento interdisciplinar, está diante do compromisso social de contribuir com esta parcela da população, colaborando para o aprendizado de português das pessoas surdas e a consequente diminuição das restrições de convivência entre comunidade surda e ouvintes.

Para delimitar a pesquisa, foram consideradas as unidades gráficas essenciais em um livro ilustrado: cor, imagem e texto. A cor é o elemento gráfico que primeiro é percebido, podendo auxiliar na organização dos elementos visuais. As imagens têm grande poder de síntese, atuando na memória e facilitando a aprendizagem. O texto tem como característica a precisão e é o código central na comunicação verbal dos livros (físico ou digital).

As obras literárias buscam a liberdade do faz de conta para quebrar as paredes de uma realidade comandada por leis naturais e físicas. Apresentam um universo ilimitado e sedutor. Especificamente para o público infantil, as histórias digitalmente animadas e interativas apresentam elevado potencial no universo das narrativas, visto que estas utilizam elementos de design interativo e reforçam cognitivamente a transmissão dos conteúdos, através dos recursos visuais, explica Crenzel (2009).

\footnotetext{
${ }^{1}$ Alves. M. M., Battaiola A. L. \& Cezarotto M. A. | Representação gráfica para a inserção de elementos da narrativa na animação educacional. Revista Brasileira de Design da Informação / Brazilian Journal of Information Design São Paulo | v. 13 | n. 1 [2016], p. 1 - 21 | ISSN 1808-5377
} 
Para este trabalho, o livro adaptado foi a versão digital (disponível em DVD) de "Guilherme Augusto Araújo Fernandes" de Mem Fox (2005). A partir da narrativa e das ilustrações originais de Julie Vivas foram desenvolvidas e adequadas novas versões das personagens incluindo sua conceituação, model sheets. Na etapa seguinte, segundo requisitos técnicos e teóricos inerentes à pesquisa, curtas animações das ações das personagens nas principais cenas foram elaboradas e implementadas para uma nova versão do livro digital.

\section{Contexto histórico-cultural da surdez}

No Brasil, como em muitos países, há um número significativo de pessoas surdas. Segundo o censo realizado em 2010 pelo Instituto Brasileiro de Geografia e Estatística (IBGE), 5,1\% da população brasileira possuía alguma perda auditiva, cerca de 9,7 milhões de pessoas. Desta porção, uma parcela de 344,2 mil representava a comunidade de surdos no Brasil (SBO/IBGE, 2013). O estado do Maranhão tem um total de 349 mil deficientes auditivos, sendo 10 mil a parcela de surdos.

Referente a idade, cerca de 1 milhão de deficientes auditivos são crianças e jovens até 19 anos. Revelou-se também que o maior número de deficientes auditivos, cerca de 6,7 milhões, estão concentrados nas áreas urbanas.

\subsection{A experiência visual do surdo e a língua de sinais}

“O termo 'surdo' é geralmente aplicado a uma pessoa cuja diminuição da acuidade auditiva é tão extensa que não consegue comunicar com outra pessoa utilizando apenas a voz" (PEREIRA E MONTEIRO, 2011). Por essa limitação biológica o surdo necessita de outra forma para se expressar e interagir socialmente. "Uma vez tomada a surdez como um fator biológico irreversível, a constituição do sujeito surdo se dará a partir de princípios próprios da experiência visual" (CAMPOS, 2009, p. 12).

\footnotetext{
"A surdez é tão antiga quanto a humanidade. Sempre existiram surdos. O que acontece, porém, é que nos diferentes momentos históricos nem sempre eles foram respeitados em suas diferenças, ou mesmo reconhecidos como seres humanos. Desde os tempos mais remotos se sabia que havia pessoas que não ouviam e que os surdos congênitos não aprendiam a falar normalmente, por isso expressavam-se por sinais." (STROBEL, 2008, p.42)
}

Não há consenso entre pesquisadores e estudiosos sobre as características que definiriam a cultura surda, entretanto sabe-se que a organização dessa comunidade não se dá pelo status auditivo de seus componentes, mas sim pela língua que compartilham, ou seja, de sinais.

William Stokoe publicou em 1960 um estudo descritivo da Língua de Sinais Americana (ASL - American Sign Language, no original em inglês) demonstrando que a mesma possui todas as características das línguas naturais orais, sendo "uma estrutura multiarticulada e multinivelada, com base nos mesmos princípios gerais de organização que podem ser encontrados em qualquer língua" (BEHARES, 1993, p. 43 apud LODI, 2004). O trabalho de Stokoe fomentou pesquisas relacionadas às línguas de sinais em diversos países e gerou um importante movimento para a educação dos surdos. A língua de sinais "possui níveis linguísticos como fonologia, morfologia, sintaxe e semântica" bem como itens lexicais, que são, nessa situação, os sinais (na língua oralauditiva os itens lexicais são as palavras). "O diferencial entre a língua de sinais e as demais é a sua modalidade visiospacial” (LIBRAS, 2017). A tradução Libras-Língua Portuguesa, assim sendo, não se trata de mera justaposição de palavras e sinais, demandando um processo mais complexo e completo de transposição de signos. 
“Fazendo um paralelo entre a literatura, a leitura e o aprender, Deleuze (2010) nos ofereceu uma chave de interpretação de que aprender diz respeito a encontros com signos que são lançados - vários signos emitidos cotidianamente e que nos chegam (MARTINS e OLIVEIRA, 2015)". Martins e Oliveira propõem um estudo da literatura surda por meio da pedagogia visual ou pedagogia surda. Refletem também sobre como a literatura pode se fazer presente no cotidiano da vida escolar de alunos surdos por meio de aspectos visuais e tradutórios no âmbito da literatura infantil surda. $E$ lançam luzes sobre a necessidade de um aperfeiçoamento dos signos semióticos auxiliando no aprendizado surdo. E assim, mais signos serão manifestados pois o surdo aprende de modo visual e não auditivo.

\title{
2.2 O surdo bilíngue na era digital
}

Campos (2009) critica a abordagem escolar que enfatiza a linguagem escrita como fundamentalmente subordinada à condição da oralidade. A escola (representada por gestores e docentes) não deve encarar a surdez como insuficiência e, muito menos, equiparar o surdo ao ouvinte. No âmbito didático, deve prover instrumentos e métodos em seu espaço para que, durante o ciclo educacional do aluno surdo, este seja propósito e proponente de uma aprendizagem participativa, colaborando com o aperfeiçoamento pedagógico e refletindo sobre a função social da escrita. $O$ design, neste cenário, por sua natureza multidimensional e multilinguística, tem vocação para prover técnicas e/ou metodologias, tanto no espectro teórico quanto prático.

Temos uma geração de crianças que nasceram e hoje crescem em meio a uma ebulição tecnológica, utilizando dispositivos e acessando plataformas digitais diversas, "com interfaces hipermidiáticas múltiplas e multifacetadas, com possibilidades de interação por comunicação presencial e remota" (CARVALHO, 2011). Inserida nesse contexto é lógico e urgente que as diretrizes educacionais sejam norteadas pelas potencialidades benéficas da linguagem digital. O caminho natural é o da assimilação - e não o da coibição - dos aparatos digitais como assessores pedagógicos. Nogueira (2014) cita trabalhos ${ }^{2}$ que indicam a importância de se considerar as práticas de letramento multimodais no processo de inserção de alunos surdos em sala de aula regular, visibilizando a língua de sinais como primeira do surdo e o ensino do português escrito como segunda língua. Nogueira analisa que grande parte destas pesquisas também apontam o aspecto visual como bastante relevante para o processo de aprendizagem do surdo.

\begin{abstract}
Justamente porque nos ambientes digitais os significados emergem de modos variados, multimodais, não restritos à linguagem verbal, mas a uma mistura densa e complexa de linguagens (incluindo a visual), os surdos encontram formas de participar e ter acesso a um universo sígnico (RODRIGUES e ALVES, 2014, p. 5).
\end{abstract}

\section{Animação em livro digital}

Um livro digital infantil é formado a partir de uma narrativa digital, que permite soluções para conectar multimídia e interatividade com o objetivo de contar histórias. (SANTAELLA, 2013) Para o desenvolvimento de um livro digital infantil considera-se: os aspectos básicos de configuração da narrativa, sua composição e como o significado é articulado através de várias mídias para que haja uma interação verdadeira. O conceito de livro digital vem se propagando, seja como plataforma digitalizada de obra impressa ou como hipermídia próxima do multissensorial, acessível em dispositivos eletrônicos variados. (TEIXEIRA e GONÇALVES, 2015)

2 (GIORDANI, 2004; KARNOPP e PEREIRA, 2004; LODI et al, 2002; SILVA et al, 2010, 2012, entre outros) 
A imagem narrativa, associada ao audiovisual tem como apoio a internet, os jogos eletrônicos, os quadrinhos, a animação em série de TV etc. (TAVARES, 2008) As mídias digitais têm sido úteis no sentido de aumentar a apreensão do conteúdo de narrativas simples ou com propósito de aprendizagem (Murray, 2000 apud Crenzel, 2009).

Além dos livros animados disponíveis on-line, o mercado de livros digitais se constitui de
títulos adaptados da literatura infantil impressa ao meio eletrônico em forma de CD-ROM,
ou desenvolvidos especialmente para o suporte eletrônico, onde, em geral, são
incorporados os mesmos recursos dos livros na Internet, além de incluir jogos e atividades
ocultas ao longo da história, pelo que se conhece com nome de "hot spots", ou também,
paralelamente às narrativas, como atividades e recursos adicionais à história (CRENZEL,2009).

Coelho (2010), afirma que para se entender o livro, caracterizado por diferentes suportes impressos ou digitais, é preciso, inicialmente, compreender que o suporte pode agregar sentidos ao texto, mesmo que em dimensões variadas. Nos estudos de Crenzel (2009), foram registrados fortes indícios que ilustrações animadas são um poderoso recurso para facilitar a aquisição de novas palavras do vocabulário em português por crianças surdas, pois a "recontação" da história da referida pesquisa por crianças dessa amostra, mostraram indícios de que a informação visual predomina sobre a informação verbal quando apresentadas conjuntamente e reforçada pela interpretação em Libras.

Além disto, infere-se que tal metodologia pode vir a ser elemento importante na elaboração de materiais didáticos que colaborem para o processo de aquisição de conceitos - verbais ou visuais - por crianças surdas. Trata-se não somente de conteúdos literários, aprendizado do português e da leitura, mas existem inúmeras possibilidades de conteúdos e disciplinas que podem ser transmitidos através de imagens animadas (matemática ou ciências, por exemplo).

Materiais interativos com ilustrações animadas, podem ser fundamentais tanto com crianças em fase de alfabetização, como para aquelas que trabalham com conceitos mais complexos de gramática, química e física, entre outros, no ensino médio por exemplo.

\section{Metodologia}

O papel final do presente projeto foi instrumentalizar a sequência de uma pesquisa anterior a esta que busca verificar se ilustrações animadas auxiliam no aprendizado da língua escrita. A escolha do livro a ser adaptado para tal investigação coube aos pesquisadores, que seguiram critérios, como a análise do discurso verbal escrito, da tradução a Libras e imagético pictórico (não verbal). Certificaram-se também da boa qualidade narrativa do livro e de ter uma versão digital acompanhada de vídeos que contam a história em Libras. O livro escolhido foi escrito por Mem Fox e ilustrado por Julie Vivas e seu título, na versão traduzida por Gilda Aquino, é Guilherme Augusto Araújo Fernandes ${ }^{3}$.

Na história, Guilherme é um menino que mora ao lado do asilo e gosta de todos os idosos, mas gostava especialmente da Sra. Antônia Maria Diniz Cordeiro que, como ele, tem quatro nomes. Todos gostam muito dela, mas lamentam que tenha perdido a memória. Guilherme começa, então, a tentar entender o que é MEMÓRIA para tentar recuperá-la para sua amiga do asilo.

Para o desenvolvimento do projeto foi definido o seguinte planejamento, com suporte na metodologia básica de todo projeto em design considerando esta proposta já como etapa de

\footnotetext{
${ }^{3}$ Título original: Wilfrid Gordon Mcdonald Partridge
} 
problematização: a seguir foi feita coleta de dados complementares; geração de alternativas; seleção da melhor alternativa; desenvolvimento da alternativa selecionada; implementação e avaliação dos resultados. As animações foram geradas com auxílio de softwares de editoração gráfica, como Adobe Photoshop, Adobe Illustrator e Adobe After Effects.

\subsection{Pesquisa e requisitos}

Por ser função deste trabalho instrumentalizar a aprendizagem da língua portuguesa, nesse caso, o conteúdo precisa proporcionar elementos com formas que facilitem o raciocínio no encadeamento cognitivo palavra-ação $\rightarrow$ imagem, ou seja, as ações (verbos) do livro, registradas no texto em português, devem condicionar a elaboração da ilustração animada e sua composição visual.

Os cenários e personagens foram refeitos para ambientá-los à realidade étnica brasileira e, em especial, dos tipos físicos presentes no Maranhão. Visto que a população maranhense é composta em sua maioria por negros - 74\%, segundo IBGE (2010), é natural que a concepção dos personagens atenda esse requisito.

Além dos requisitos conceituais, outras exigências técnico-gráficas complementares foram adotadas:

Tabela 1 - Requisitos do projeto

\begin{tabular}{ll}
\hline Requisitos técnicos & Requisitos da ilustração \\
\hline 25 frames por segundo & Design amigável \\
$\begin{array}{l}\text { Resolução do vídeo de saída da } \\
\text { animação: } 1280 x 800 \text { pixels }\end{array}$ & Estilo de ilustração com poucos traços \\
Formato widescreen & Paleta de cores reduzida \\
Duração: entre 5 e 15 segundos & Alto contraste figura-fundo \\
\hline
\end{tabular}

Fonte: elaborado pelo autor

Em pesquisa realizada pelos autores em 2016 buscou-se compreender algumas questões do aprendizado de crianças surdas interagindo com livros digitais animados traduzidos em Libras. Crianças surdas foram entrevistadas em ambiente escolar (Escola Municipal Bandeira Tribuzzi, São Luís - MA). Logo após cada interação, uma lista de palavras era mostrada para que a criança apontasse quais termos teria identificado ou entendido minimamente o conceito. Em seguida - com intermediação de uma intérprete -, as mesmas foram solicitas a contarem, do ponto de vista de cada uma, a história que acabaram de ver.

Figura 1. Captura de tela do livro em versão traduzida em Libras e ilustração animada. Pág. 1 / Tradutora sinalizando "Guilherme" / Animação Frame 2. 

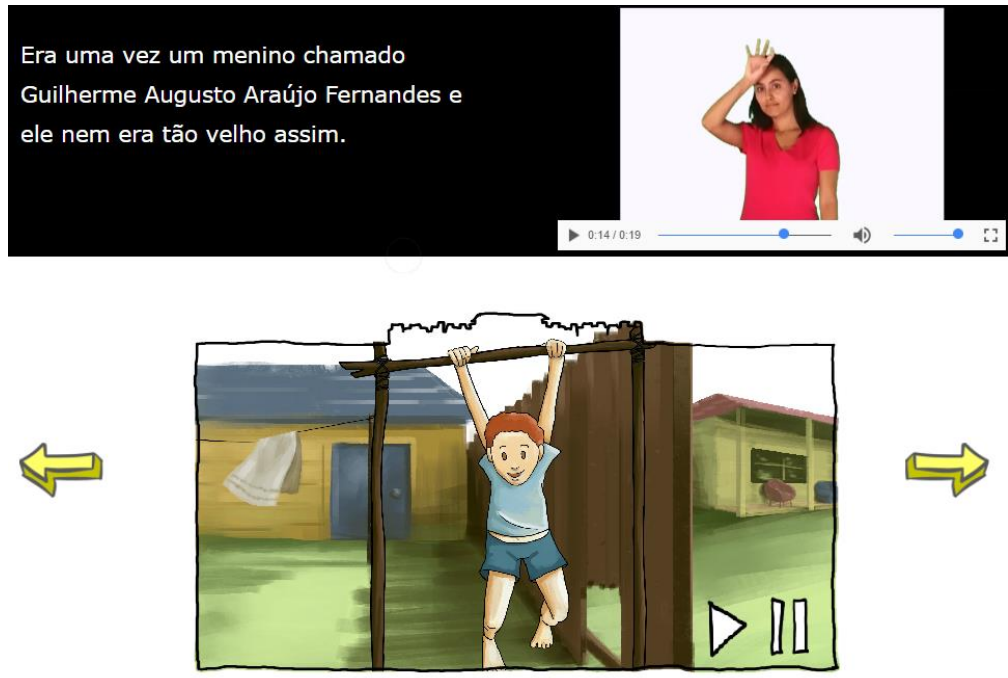

Sumário Páq. 1 Páq. 2 Pág. 3 Pág. 4 Pág. 5 Pág. 6 Páq. 7 Pág. 8 Pág. 9 Pág. 10 Pág. 11 Pág. 12 Pág. 13 Páq. 14 Pág. 15 Pág. 16 Páq. 17 Pág. 18 Páq. 19 Páq. 20 Páq. 21 Pád. 22 Páq. 23 Páq. 24 Páq. 25 Páq. 26 Pág. 27 Pág. 28 Pád. 29 Fim

Fonte: elaborado pelo autor

Foram testadas duas versões do livro digital com tradução em Libras, uma com ilustrações estáticas e outra com ilustrações animadas. As crianças puderam interagir com o livro por meio de um notebook e manuseando um mouse passavam as páginas e davam play no vídeo da intérprete de Libras e no vídeo da animação (quando na versão animada). A partir disso, foram feitas anotações que serviram como parâmetros para análise e a correção mais adequada fosse apresentada nas etapas seguintes do projeto. Problemas como, por exemplo, alguns textos muito grandes nas páginas (fig. 2), podem dificultar a leitura e dispersar o interesse das crianças pela história.

Figura 2. Captura de tela do livro em versão traduzida em Libras e ilustração animada. Pág. 10 / Frame 1.
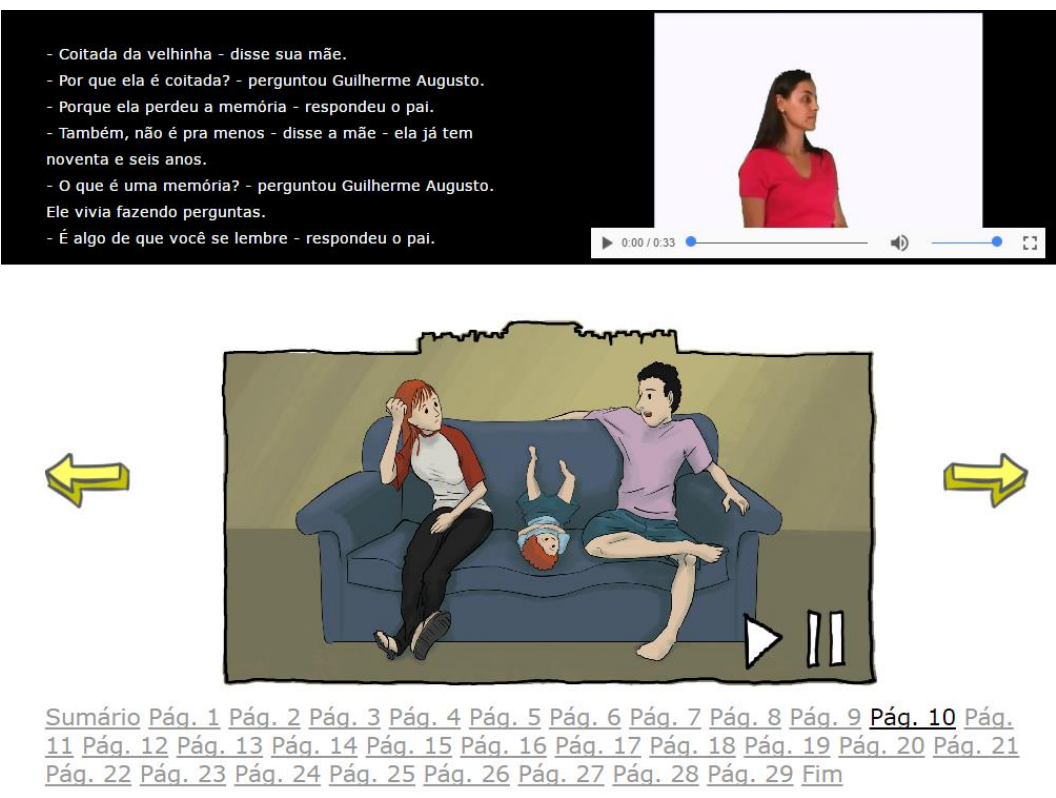

Fonte: elaborado pelo autor 
Os relatos de duas crianças fazem uma menção a cor dos objetos na animação:

- "O moço entrega uma medalha amarela e vai embora" (H, menina).

- Ele fala que o dinheiro "é amarelo" ( $\mathrm{J}$, menino).

Presume-se destas falas que a influência da cor pode atuar na memorização da história. De acordo com Pauli (2004, apud WITTER, RAMOS, 2008), "as cores são vistas como se fizessem parte da aparência dos objetos, criando uma associação entre ambos; a cor das nuvens, a cor da fachada da casa, a cor do vestido, a cor do carro."

\section{Desenvolvimento}

A partir do roteiro da narrativa do livro Guilherme Augusto Araújo Fernandes foram desenvolvidos os cenários e as cenas animadas.

Apesar da geração de ideias ser uma etapa que exige um desprendimento maior do resultado animado, ainda assim, precisa acompanhar os requisitos pré-estabelecidos.

Figura 3. Geração de alternativas para caracterização dos personagens Guilherme e Antônia

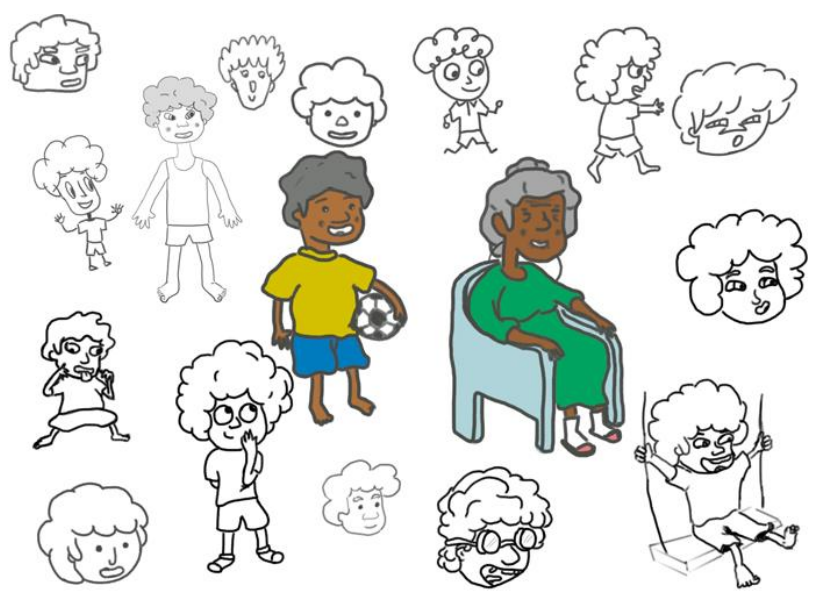

Fonte: elaborado pelo autor

Escolhido o estilo da ilustração para o personagem, parte-se para seu desenvolvimento visual. Escolheu-se fazer os rascunhos em papel e em seguida, com auxílio de software de edição gráfica, os desenhos foram finalizados.

Figura 41. Desenho dos personagens finalizados no Photoshop.
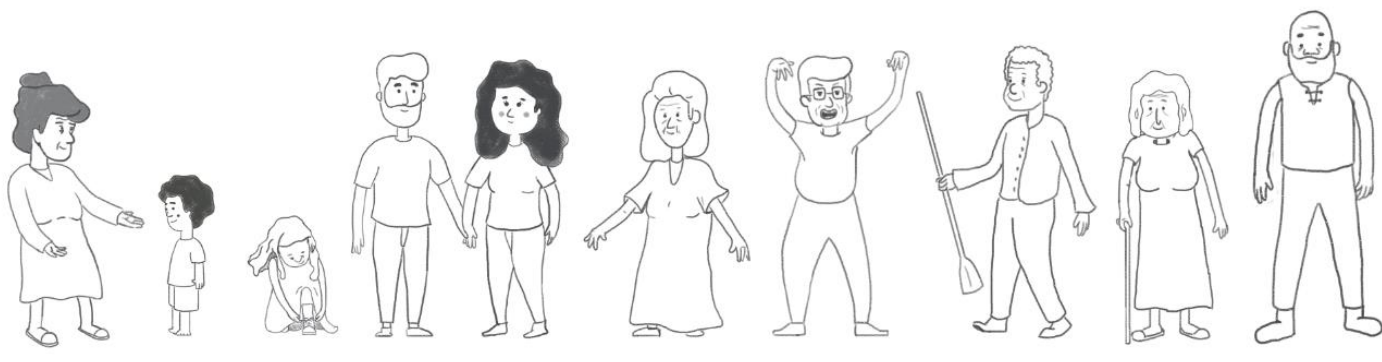

Fonte: elaborado pelo autor 
O model sheet (folha do modelo) do personagem é uma folha que deve apresentar o personagem. Essa folha pode servir como modelo para animadores, e todos os demais designers e artistas envolvidos. Nele podem ser marcadas as expressões, detalhes da construção da estrutura, e o que mais for preciso para facilitar o trabalho de redesenho (CAMARA, 2006 apud Silva, 2013).

Figura 52. Model sheet dos personagens Guilherme e senhora Mandala
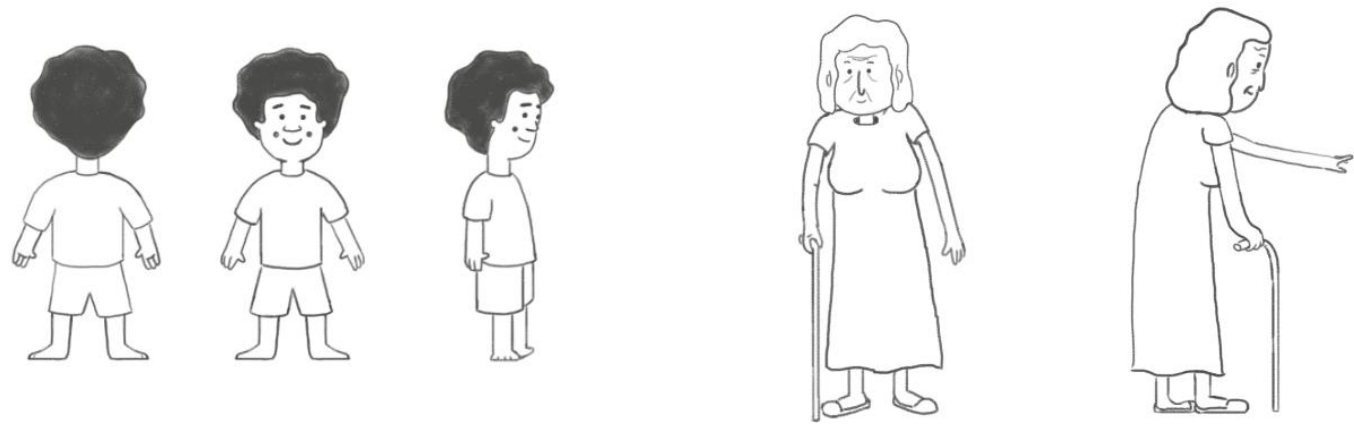

Fonte: elaborado pelo autor

O cenário principal da página 2 (fig. 6) foi refeito tendo como referência casas de telhado comuns na paisagem brasileira e nos centros de São Luís.

Figura 6. Cenário da página 2.

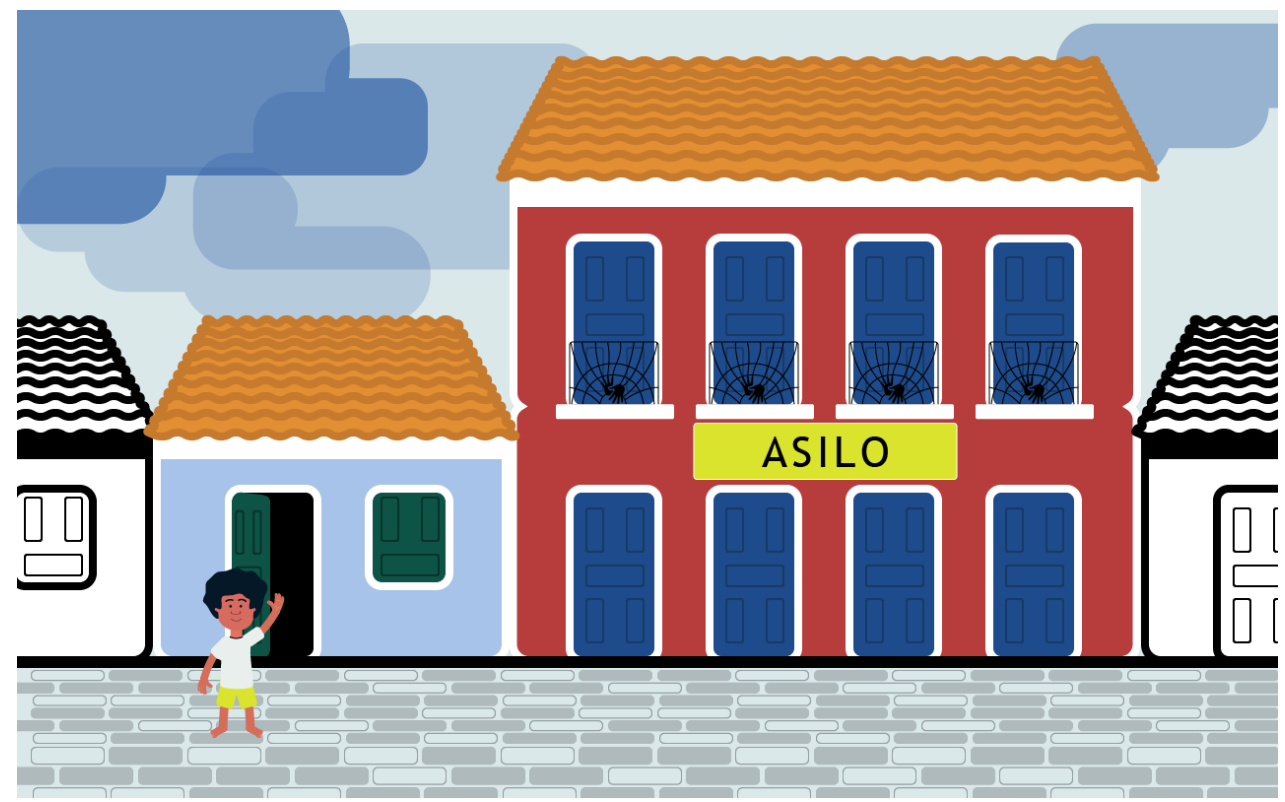

Fonte: elaborado pelo autor

O storyboard (fig. 7) é uma das etapas mais importantes na produção de uma animação. Contém todo o conceito visual como o enquadramento, cortes e movimento de câmera, além de localizar os ambientes e inserir as personagens em cena. A cena quando planejada no storyboard evita o retrabalho de horas na animação final. (LAYBOURNE, 1998 apud Silva, 2013) 
Elaborou-se o storyboard das cenas, baseado nas ilustrações do livro impresso e também em quais movimentos as personagens fariam durante suas ações, descrevendo-as na legenda do storyboard.

Figura 7. Storyboard - Página 2.

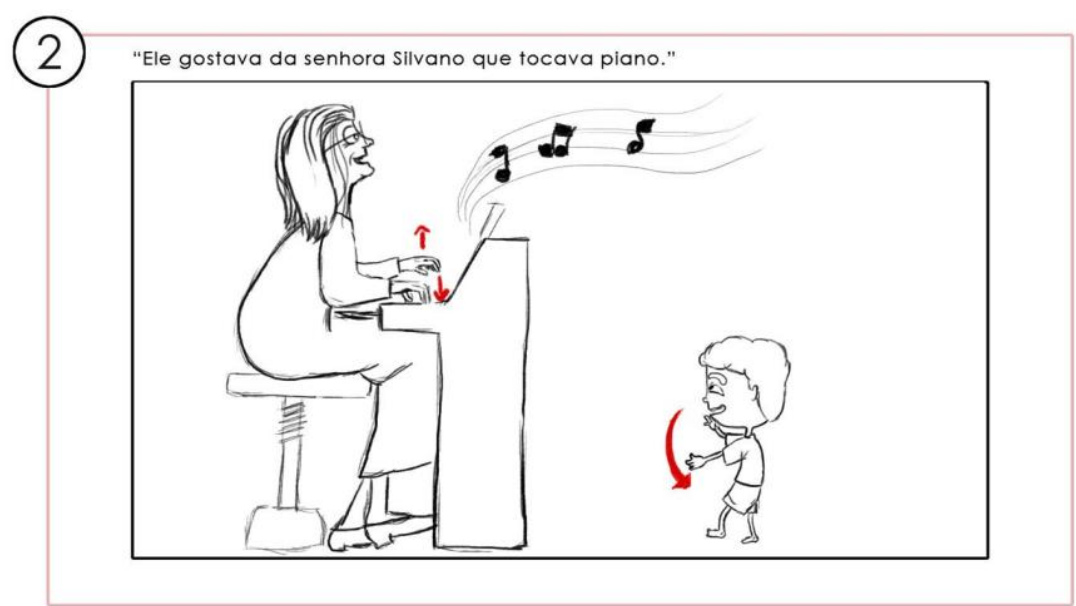

As mãos da Sra. Silvano se movimentam para cima e para baixo, enquanto as notas musicais flutuam no ar.

Guilherme dança balançando os braços.

Fonte: elaborado pelo autor

As cores são elementos primordiais desse projeto, pois como traçado nos requisitos devem fazer um destaque entre a figura principal da cena e o fundo da animação. Foi estabelecida uma paleta reduzida para que cada personagem fosse mais facilmente identificável e memorizado. A cor tem o papel também de hierarquizar e agrupar os protagonistas e coadjuvantes da história.

Figura 8. Personagens da animação em cores

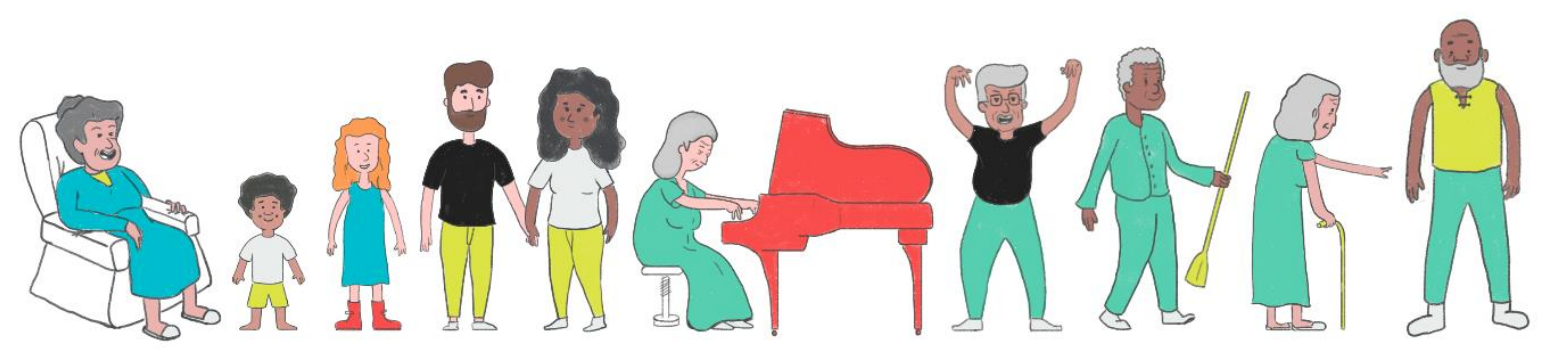

Fonte: elaborado pelo autor

Para o processo de animação os desenhos digitalmente finalizados foram transpostos no software Illustrator para que cada cena fosse preparada para animação.

Figura 9. Ilustração de Guilherme sendo preparada no Adobe Illustrator. 


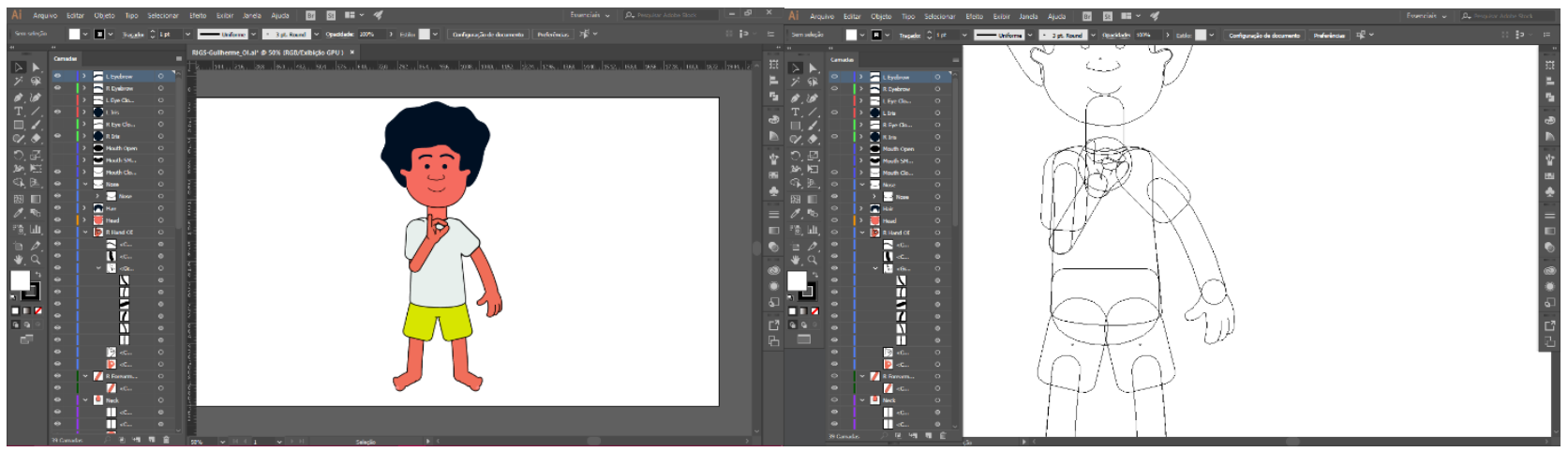

Fonte: elaborado pelo autor

Em sequência o arquivo feito no Illustrator é importado na área de trabalho do programa Adobe After Effects, onde são criados os bones do personagem, que funcionam como controladores das partes que serão animadas no personagem.

Figura 10. Animação do personagem no After Effects.

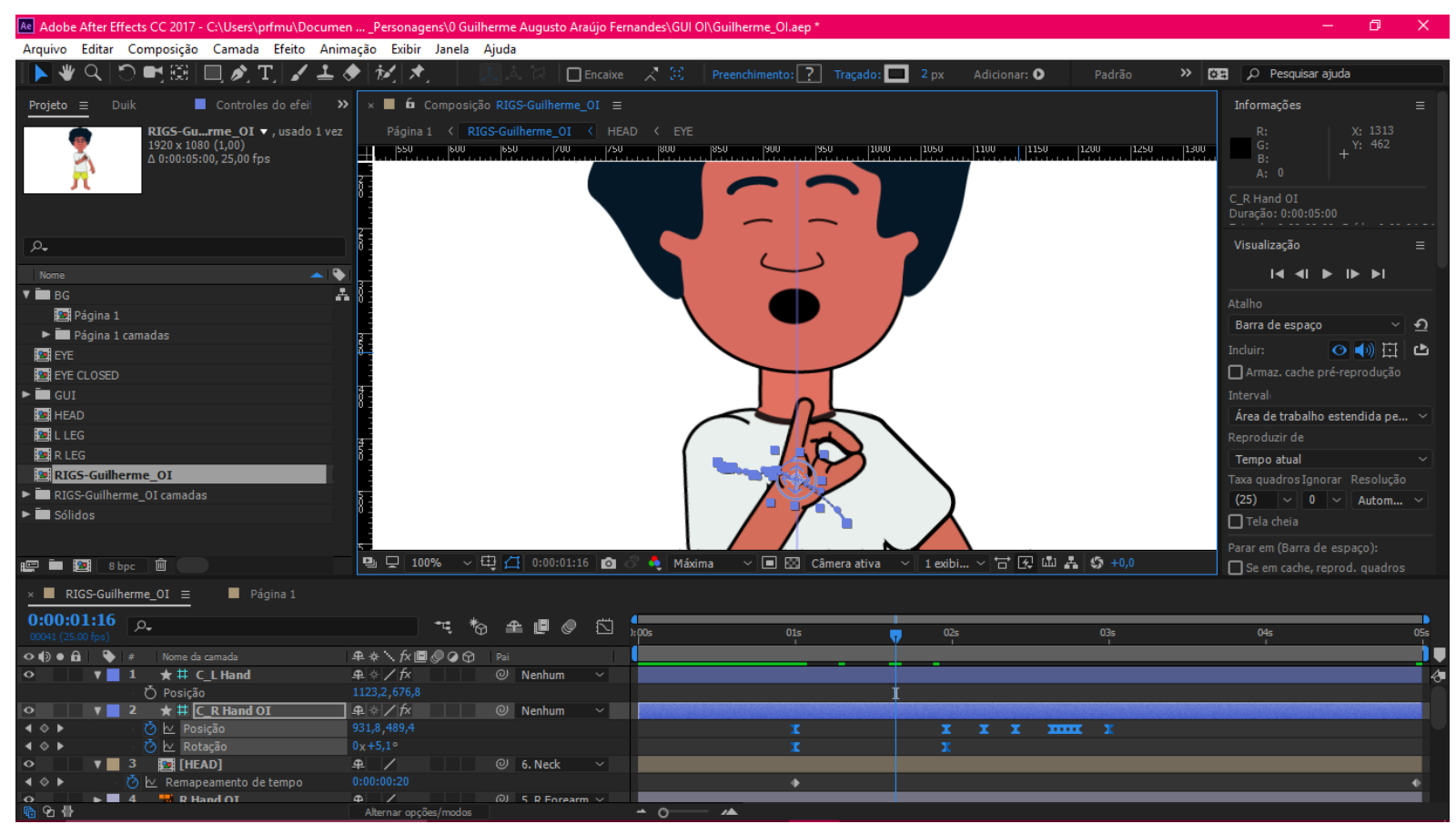

Fonte: elaborado pelo autor

Figura 11. Animação da personagem Silvano. 


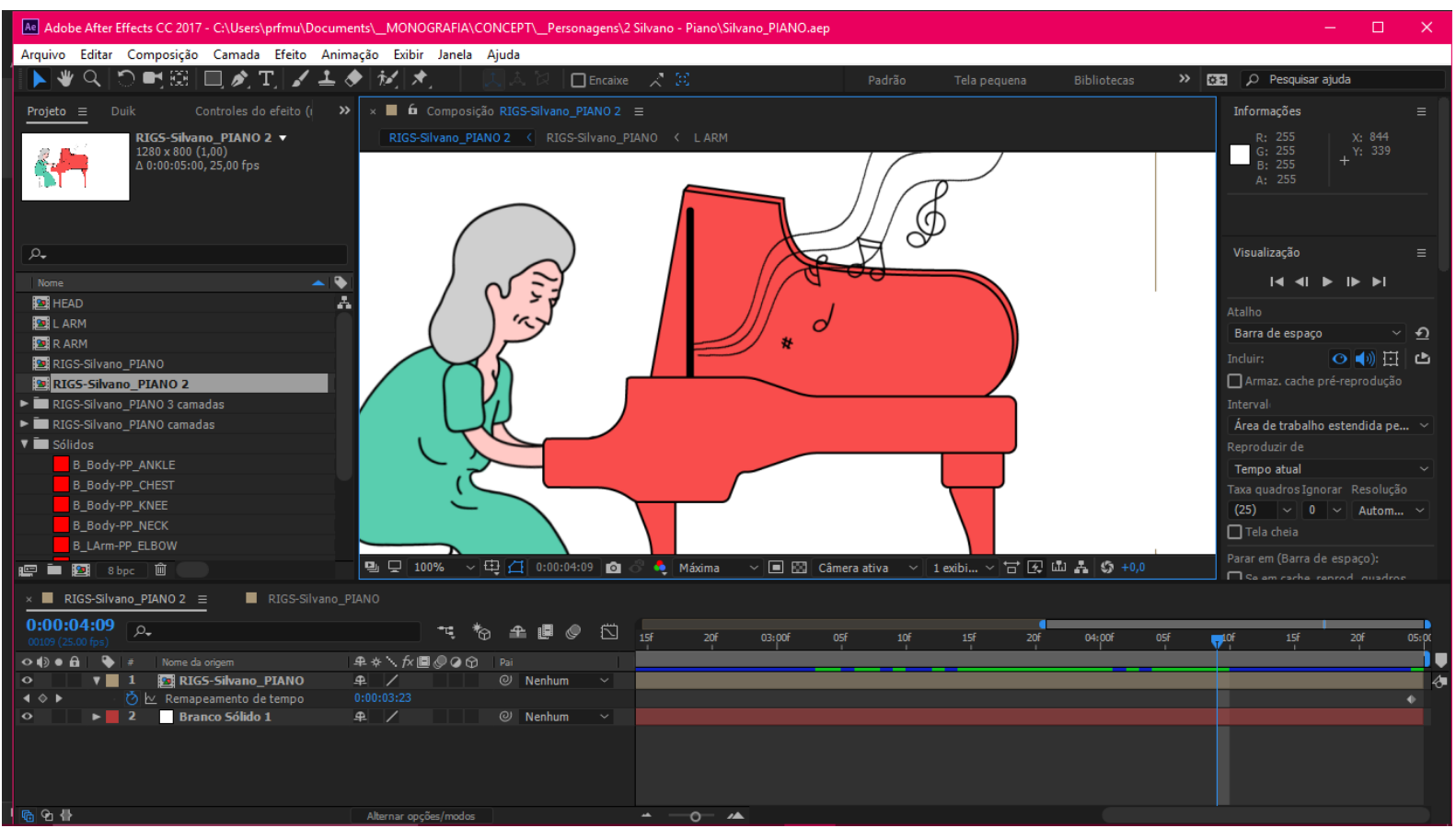

Fonte: elaborado pelo autor

\section{Conclusão}

A criação de conhecimento dá-se em camadas. Cada camada corresponde a um acréscimo ao conhecimento anterior. $O$ design é uma disciplina que não se restringe à geração de produtos esteticamente agradáveis: o design é uma disciplina que contribui socialmente e colabora na construção do conhecimento.

Pode-se considerar essa pesquisa como uma primeira camada num campo específico do conhecimento e a produção aqui relatada, e demonstrada, como a segunda. Entretanto, o tema abordado é de grande importância social por ter como proposta criar materiais lúdicos e paradidáticos para auxiliar a incluir pessoas surdas na sociedade e, portanto, entende-se que o esforço iniciado em 2014 não pode ser dado como encerrado. Baseada na história escolhida, foi apresentada uma análise que ultrapassa esta proposta inicial, pois identifica pontos que podem ser melhorados, uma vez que juntamente com tradução de narrativas infantis para Libras, as animações desenvolvidas oportunizam às crianças surdas conhecimento de histórias que fortalecem a identidade cultural surda e expandem o alcance de sua integração na sociedade. Futuramente, espera-se, também, que sirva como embrião para um projeto de produção de materiais lúdicos e paradidáticos que venha a beneficiar crianças surdas.

Através dos resultados desta pesquisa será possível contribuir para criação de ferramentas para o planejamento de objetos educacionais e para a melhoria nos padrões educacionais de crianças surdas, a fim de se conseguir uma aprendizagem mais produtiva e interativa.

Como desdobramento espontâneo desta pesquisa está sendo desenvolvido - em caráter experimental -, um site (http://bit.ly/guilherme-libras) em fase de protótipo para fins de observação e testes preliminares ainda a serem aplicados. 


\section{Referências}

Alves. M. M., Battaiola A. L. \& Cezarotto M. A. | Representação gráfica para a inserção de elementos da narrativa na animação educacional. Revista Brasileira de Design da Informação / Brazilian Journal of Information Design São Paulo | v. 13 | n. 1 [2016], p. 1 - 21 | ISSN 1808-5377

CAMPOS, Sandra Regina Leite de. Aspectos do processo de construção da língua de sinais de uma criança surda filha de pais ouvintes em um espaço bilíngue para surdos. 2009. Dissertação (Mestrado em Educação) - Faculdade de Educação, Universidade de São Paulo, São Paulo, 2009.

CARVALHO Neto, Cassiano Zeferino de. Educação digital: paradigmas, tecnologias e complexmedia dedicada à gestão do conhecimento. Tese EGC/UFSC - Universidade Federal de Santa Catarina, Florianópolis, 2011.

COELHO, Nelly Novaes. Literatura infantil: teoria, análise, didática. 1 ed. São Paulo: Moderna, 2010. CRENZEL, Silvina Ruth. A ilustração infantil como recurso narrativo: influência das imagens na leitura de histórias por crianças. Tese (Doutorado) - Programa de Pós-graduação em Artes \& Design, Pontifícia Universidade Católica, Rio de Janeiro, 2009.

Silvina Ruth. A animação como recurso narrativo para crianças surdas. Relatório de pesquisa desenvolvida como parte dos requisitos para obtenção de certificado de estágio pósdoutoral. São Luís: UFMA, 2016.

FOX, Mem. Guilherme Augusto Araújo Fernandes. Ilustração de Julie Vivas. Tradução de Gilda Aquino. São Paulo: Brinque-Book, 2005.

GESUELI, Zilda Maria. A escrita como fenômeno visual nas práticas discursivas dos alunos surdos. In: LODI, A.C.B.; HARRISON, K.M.P.; CAMPOS, S.R.L. (orgs.) Leitura e escrita: no contexto da diversidade. Porto Alegre: Editora Mediação, 2004.

Instituto Brasileiro de Geografia e Estatística - IBGE. (2010). Censo Demográfico - 2010. Maranhão: IBGE. Disponível em <www.ibge.gov.br> acessado em 15 de março de 2017

LIBRAS. O que é Libras? Publicado em 17 de maio de 2017. Disponível em <http://www.libras.com.br/o-que-e-libras> acessado em 31 de janeiro de 2018.

LODI, Ana Claudia Balieiro. Uma leitura enunciativa da língua brasileira de sinais: o gênero contos de fadas. DELTA, São Paulo, v. 20, n. 2, p. 281-310, Dec. 2004. Disponível em <http://www.scielo.br/scielo.php?script=sci_arttext\&pid=S0102-

44502004000200005\&lng=en\&nrm=iso> acessado em 16 de março de 2018.

MARTINS, Vanessa Regina de Oliveira; OLIVEIRA, Guilherme Silva de. Literatura surda e ensino fundamental: resgates culturais a partir de um modelo tradutório com especificidades visuais. Educ. Soc., Campinas, v. 36, n. 133, p. 1041-1058, dezembro 2015. Disponível em <http://www.scielo.br/scielo.php?script=sci_arttext\&pid=S0101-

$73302015000401041 \&$ Ing=en\&nrm=iso> acessado em 05 de abril de 2018

MAYBERRY, R. I. \& Eichen, E. B. The long-lasting advantage of learning sign language in childhood: Another look at the critical period for language acquisition. Journal of Memory and Language, 30, 486-512, 1991. 
NOGUEIRA, Aryane Santos. Práticas de Letramento multimodais em Ambiente digital: uma possibilidade para repensar a educação de surdos. Revista Intercâmbio, v. XXVIII: 19-45, 2014. São Paulo: LAEL/PUCSP. ISNN 2237-759x

PEREIRA, Maria Inês; MONTEIRO, Luísa. Surdez nas crianças. Programa Harvard Medical School Portugal, 2011. Disponível em <https://hmsportugal.wordpress.com/2011/10/09/surdez-nascriancas > acessado em 13 de março de 2018

RODRIGUES, Patrícia Rocha; ALVES, Lynn Rosalina Gama. Criar e compartilhar games: novas possibilidades de letramento digital para crianças surdas. RENOTE - Revista Novas Tecnologias na Educação, v. 12, n. 2, 2014. Rio Grande do Sul: CINTED/UFRGS. ISSN 1679-1916

SANTAELLA, Lucia. Comunicação ubíqua: Repercussões na cultura e na educação. São Paulo: Paulus, 2013.

SBO/IBGE. Deficiência auditiva atinge 9,7 milhões de Brasileiros. 2013. Disponível em <http://www.adap.org.br/site/index.php/artigos/20-deficiencia-auditiva-atinge-9-7-milhoes-debrasileiros> acessado em 31 de janeiro de 2018

SILVA, Andrey Parmigiani da. Desenvolvimento de personagem toy art como representação conceitual de marca. Trabalho de Conclusão de Curso do Curso de Design. Joinville - Santa Catarina: UNIVILLE, 2013

TAVARES, Romero. Construindo mapas conceituais. Ciências \& Cognição, 2008; v. 13, n.2, 99 - 108, 2008.

TEIXEIRA, Deglaucy Jorge. GONÇALVES, Berenice Santos. A hipermídia como expressão do conteúdo dramático em narrativa digital interativa: uma análise em livro digital interativo infantil. InfoDesign Revista Brasileira de Design da Informação, São Paulo, v. 12, n. 1, p.1-15, 2015. ISSN 1808-5377

WITTER, G.P.; RAMOS, O. A. Influência das cores na motivação para leitura das obras de literatura infantil. Associação Brasileira de Psicologia Escolar e Educacional (ABRAPEE), v.12, p. 37-50, 2008. 